\title{
Managing Study Stress of College Students Through Personality Traits
}

\author{
Ding DING ${ }^{\mathrm{a}, \uparrow}$, Xinyue LIU ${ }^{\mathrm{b}, \uparrow}$ and Haoran XU ${ }^{\mathrm{c}, 1}$ \\ ${ }^{a}$ North China Electric Power University, China \\ ${ }^{b}$ School of Business, University of Wollongong, NSW 2522 Australia \\ ${ }^{c}$ Alliance Business School, University of Manchester, Manchester, UK \\ These authors contributed equally.
}

\begin{abstract}
University students' stress management is a core topic in educational research; however, limited research has ever focused on how personality would impact students' perception of stress level. Thereby, this quantitative study, based on the Big Five Personality Trait Model, set out to investigates how openness, conscientiousness, extraversion, agreeableness, and neuroticism affect the college students' perception of their study stress. As a result of a survey with sixty college students in China, it is found that whilst students' demographic factors may not significantly predict their stress level, psychographic factors including conscientiousness, agreeableness and neuroticism can positively and significantly determine the college students' perception of stress. Based on the findings of the study, implications for future students' mental health management and ensuing educational research are put forward.
\end{abstract}

Keywords. Personality, Stress management, College students, Higher Education

\section{Introduction}

University life could be innately with high stress, manifested from paying for expensive tuition fees to taking exams and to looking for internships and jobs after graduation. Such overwhelming pressure, if handled inappropriately, could lead to negative consequences to students' physical and psychological conditions. In this situation, college students' stress management has been becoming an increasingly significant research domain for both academia and higher education practitioners [1].

Given the fact that the stress issue is prominent, there must be reasons for causing the stress. Previous studies have found that multifarious factors can influence the students' stress perception level, including but not limited to college course-related requirements, personal lifestyles and social connections [2]. Based on these factors, pertinent recommendations to release their stress have been simultaneously put forward, such as by noticing the symptoms, enhancing the social network, sleeping, eating well and doing more exercise [3].

Nonetheless, few extant studies have focused on how personal characteristics, or personality, impact students' stress levels. In accordance with previous psychology research, it can be said that personality traits could be more essential to explain the

\footnotetext{
${ }^{1}$ Corresponding author. Alliance Business School, University of Manchester, Manchester, UK; Email: haoran.xu-2@postgrad.manchester.ac.uk.
} 
differences in stress level among college students [4]. In this context, this study attempts to investigate the mechanism between college students' personality and their stress levels. In the next section, based on previous literature, an array of hypotheses is made for further testing based on the collected empirical data.

\section{Hypotheses Development}

Personality can be defined as 'a set of distinctive traits and characteristics' and has been used as a valid predictor for human behaviors. In this study, personality would be selected as the independent variable to detect its influence on college students' stress levels.

To measure college students' personality traits, whilst there are distinct personality measurement models, the Big Five Personality Trait Model is one of the most implicative models frequently used to quantify ones' personality. Five dimensions included in the model are openness to experience, conscientiousness, extraversion, agreeableness, and neuroticism [5].

Respectively, openness denotes how open a person is to new ideas and experiences; conscientiousness means how goal-directed, persistent, and organized a person is; extraversion is used to describe how much a person is energized by the outside world; Agreeableness relates to people displaying a capability of unselfishness, altruism and caring [6]; finally, neuroticism refers to one's tendency to face difficulty and stress with calmness, resolve, and security [7].

The Big Five model of personality is universally believed to be one of the most scientific and robust methods to measure personality differences. It is also the foundation of modern personality research [8] and is thereby adopted in this study to measure college students' personality traits. According to previous studies [9-10], these five factors can be hypothesized to be positively related to the factor of students' stress level, reacted as the dependent variable in this study. Finally, these hypotheses can be tested among college students in this study.

Aside from the five hypotheses with respect to personalities, two demographics factors are also included in the survey including sex and educational level, aiming to examine whether one's demography would impact the stress perception. Finally, the hypotheses made in this study are delineated in Table 1.

Table 1. Hypotheses made in this study.

\begin{tabular}{ll}
\hline Hypothesis & Description \\
\hline H1 & Gender would significantly impact college students' stress level \\
H2 & Educational level would significantly impact college students' stress level \\
H3 & Open to experience would significantly and negatively impact college students' stress level \\
H4 & Conscientiousness would significantly and positively impact college students' stress level \\
H5 & Extraversion would significantly and negatively impact college students' stress level \\
H6 & Agreeableness would significantly and positively impact college students' stress level \\
H7 & Neuroticism would significantly and positively impact college students' stress level \\
\hline
\end{tabular}




\section{Methods}

This study was conducted quantitatively, using a survey method to collect pertaining data to answer the research questions and hypotheses.

To begin with, with respect to the questionnaire design process, a questionnaire referring to the original big five personality was employed, resulting in a scale of one to five. These data would be used to measure their personality traits. As for the perceived stress level, a 5-point likert scale is used to measure students' perception of the study pressure. The questionnaire also included the data to collect students' demographics information including age, gender, major and educational level.

Regarding the data collection process, the survey questions were all transformed in the E-questionnaire using WeChat Form, which is an online survey platform and distributed through WeChat to Chinese higher education students. Then, these surveys were sent out using the convenience and snow-ball sampling methods, which is a type of non-probability method. As a result, 60 questionnaires collected without any missing data were included for data analysis.

As to the data analysis, the data were analysed through Excel and SPSS. More specifically, a descriptive analysis was conducted first to show the profile of the respondents. Then, mean tests, including independent sample t-test and one-way ANOVA were made to test the hypothesis one and two. After that, hypothesis three to seven are tested by the correlation test in SPSS. The results are shown in the next section.

\section{Results}

Table 2 shows the demographic information of the respondents. It is found that the collected data has covered the major demographic segments, showing that the sample collected can be used to implicate the population's (all the college students') conditions.

Table 2. Demographic profile of respondents.

\begin{tabular}{lll}
\hline Variable & & Frequency (n=60) \\
\hline Age & 21 & 9 \\
& 22 & 10 \\
& 23 & 21 \\
& 24 & 15 \\
& 25 & 10 \\
& 26 & 5 \\
& & 32 \\
\hline Gender & Male & 28 \\
\hline Educational level & Female & 30 \\
& Bachelor & 22 \\
& Master & 8 \\
\hline
\end{tabular}

As for the mean test, independent sample t-test was conducted to detect whether gender can significantly impact college students' perceptions of stress (Table 3). The results show that gender had no significant impact on the college students' stress perception $(\mathrm{p}>0.05)$. 
Table 3. The mean test of student stress (gender)

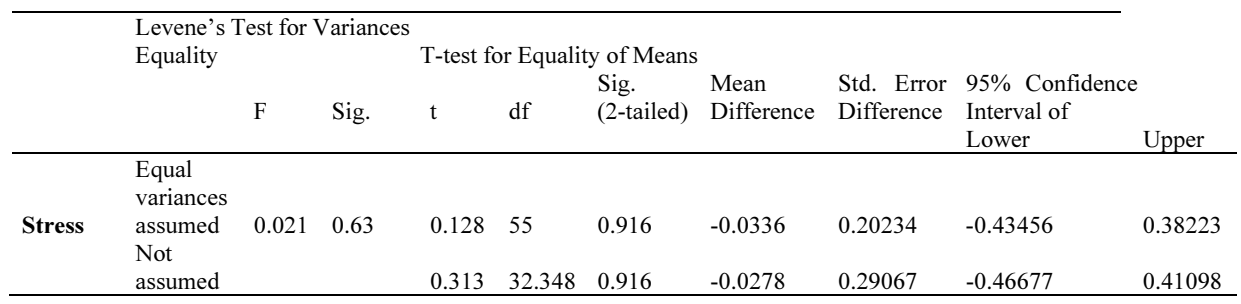

Then, one-way Anova tests were performed to determine whether students with different educational levels would have distinct perceptions of study stress. The results reveal that there has been no significant difference among students with distinct educational background.

Table 4. One-way ANOVA (Education).

\begin{tabular}{|c|c|c|c|c|c|c|}
\hline $\begin{array}{l}\text { (I) } \\
\text { EDUCATION }\end{array}$ & $\begin{array}{l}\text { (J) } \\
\text { EDUCATION }\end{array}$ & $\begin{array}{l}\text { Mean Difference } \\
\text { (I-J) }\end{array}$ & $\begin{array}{l}\text { Std. } \\
\text { Error }\end{array}$ & Sig. & \multicolumn{2}{|c|}{ 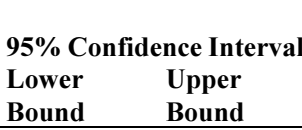 } \\
\hline Bachelor & $\begin{array}{l}\text { Master } \\
\text { PhD }\end{array}$ & $\begin{array}{l}0.45558 \\
0\end{array}$ & $\begin{array}{l}0.28802 \\
0.30662 \\
\end{array}$ & $\begin{array}{l}0.119 \\
1 \\
\end{array}$ & $\begin{array}{r}-0.1205 \\
-0.6136 \\
\end{array}$ & $\begin{array}{l}1.0322 \\
0.6136 \\
\end{array}$ \\
\hline Master & $\begin{array}{l}\text { Bachelor } \\
\text { PhD }\end{array}$ & $\begin{array}{l}-0.45558 \\
-.45558^{*}\end{array}$ & $\begin{array}{l}0.28802 \\
0.20655 \\
\end{array}$ & $\begin{array}{l}0.119 \\
0.031 \\
\end{array}$ & $\begin{array}{l}-1.0322 \\
-0.8692 \\
\end{array}$ & $\begin{array}{l}0.1205 \\
-0.0426 \\
\end{array}$ \\
\hline PhD & $\begin{array}{l}\text { Bachelor } \\
\text { Master }\end{array}$ & $\begin{array}{l}0 \\
.45558 *\end{array}$ & $\begin{array}{l}0.30662 \\
0.20655\end{array}$ & $\begin{array}{l}1 \\
0.031\end{array}$ & $\begin{array}{l}-0.6136 \\
0.0426\end{array}$ & $\begin{array}{l}0.6136 \\
0.8692\end{array}$ \\
\hline
\end{tabular}

*The mean difference is significant at the 0.05 level.

Thus, both $\mathrm{H} 1$ and $\mathrm{H} 2$ needs to be rejected. In other words, the demographic factors are not effective predictors to forecast college students' study stress level. Eventually, correlation tests were made to test $\mathrm{H} 3$ to $\mathrm{H} 7$ (Table 5).

Based on the correlation test results, it is shown that conscientiousness, agreeableness, and neuroticism were statistically and significantly positively correlated with the perceived stress level, but openness and extraversion were not, which means that $\mathrm{H} 3$ and $\mathrm{H} 5$ should be rejected and $\mathrm{H} 4, \mathrm{H} 6$ and $\mathrm{H} 7$ can be initially accepted.

\section{Discussion and Conclusion}

In conclusion, as can be seen from the above results, this study firstly confirms that demographic factors are not significant predictors to monitor student's mental health conditions. In comparison, personalities are more valid and reliable to be considered when predicting college students' study stress levels. This finding is consistent with previous studies [11-12].

More specifically, this study also confirms that not all personality traits can be used to forecast students' study stress levels. As can be found in this article, three types of personality traits including conscientiousness, agreeableness and neuroticism would significantly impact one's stress level. Therefore, they should be adopted as more powerful indicators to predict college students stress levels. 
Table 5. Correlation tests results.

\begin{tabular}{|c|c|c|c|c|c|c|c|}
\hline & & Openness & $\begin{array}{l}\text { Conscienti } \\
\text { ousness }\end{array}$ & Extraversion & Agreeableness & Neuroticism & Stress \\
\hline \multirow[t]{3}{*}{ Openness } & $\begin{array}{l}\text { Pearson } \\
\text { Correlation }\end{array}$ & 1 & 0.567 & 0.555 & 0.689 & 0.567 & .086 \\
\hline & Sig. (2-tailed) & 0 & 0 & 0 & 0 & 0 & 0 \\
\hline & $\mathbf{N}$ & 60 & 60 & 60 & 60 & 60 & 60 \\
\hline \multirow[t]{3}{*}{$\begin{array}{l}\text { Conscientiousn } \\
\text { ess }\end{array}$} & $\begin{array}{l}\text { Pearson } \\
\text { Correlation }\end{array}$ & & 1 & 0.655 & 0.98 & 0.777 & $.586^{* *}$ \\
\hline & Sig. (2-tailed) & & 0 & 0 & 0 & 0 & 0 \\
\hline & $\mathbf{N}$ & & 60 & 60 & 60 & 60 & 60 \\
\hline \multirow[t]{3}{*}{ Extraversion } & $\begin{array}{l}\text { Pearson } \\
\text { Correlation }\end{array}$ & & & 1 & 0.554 & 0.134 & 0.454 \\
\hline & Sig. (2-tailed) & & & 0 & 0 & 0 & 0 \\
\hline & $\mathbf{N}$ & & & 60 & 60 & 60 & 60 \\
\hline \multirow[t]{3}{*}{ Agreeableness } & $\begin{array}{l}\text { Pearson } \\
\text { Correlation }\end{array}$ & & & & 1 & 543 & $.70 * *$ \\
\hline & Sig. (2-tailed) & & & & 0 & 0 & 0 \\
\hline & $\mathbf{N}$ & & & & 60 & 60 & 60 \\
\hline \multirow[t]{3}{*}{ Neuroticism } & $\begin{array}{l}\text { Pearson } \\
\text { Correlation }\end{array}$ & & & & & 1 & $.720 * *$ \\
\hline & Sig. (2-tailed) & & & & & 0 & 0 \\
\hline & $\mathbf{N}$ & & & & & 60 & 60 \\
\hline \multirow[t]{3}{*}{ Stress } & $\begin{array}{l}\text { Pearson } \\
\text { Correlation }\end{array}$ & & & & & & 1 \\
\hline & Sig. (2-tailed) & & & & & & 0 \\
\hline & $\mathbf{N}$ & & & & & & 60 \\
\hline
\end{tabular}

** Correlation is significant at the 0.01 level (2-tailed).

As a further illustration of the results, it can be implicated that when one student is more result-oriented and more sensitive toward others' opinions, he or she is more likely to experience mental health problems generated from study stress. In other words, if a student is more agreeable to the external environment, they tend to be more stressful. Other than that, students who show a more organized way of doing things and can persevere tend to feel more stress as well, as they have a stronger motivation to maintain or enhance a positive self-image and resist threats to it.

Moreover, among the Big Five personality, neuroticism has a negative effect on work pressure, leading to aggravation of emotional exhaustion. Students with high neuroticism tend to turn their faces with colleagues, which intensifies work pressure. Besides, conscientious people are hardworking, diligent, and self-disciplined, they tend to have an achievement striving motivation that is associated with a need to feel competent and accomplished [13]. Thus, students with high conscientiousness tend to have a higher level of ambition, focus more on their current main tasks, and work harder to achieve their goals, thus spontaneously avoiding irrelevant interference and pressure. However, since they can reconcile work and social, as the pressure from organizational factors increases, individuals continue to pay emotional resources, thus intensifying the pressure.

Finally, with respect to theoretical implication, it can be confirmed that the Big Five personality model is a representative of the theory of personality trait in personality psychology that can be used to probe stress perception. Hence, future theoretical construction should be more frequently based on ones' personality. Meanwhile, future 
studies may harness other personality models to study what other personality characteristics are correlated with one's stress.

Concerning the practical implications, as personality plays key roles in determining students' study stress level, future college mental health consultation should pay more attention to how to construct students' positive personalities. For instance, the personality of openness can be further cultivated for college students, as it is worth noting that high-openness employees can often reduce their stress at work through social connections due to their outgoing personality, thereby relieving their mental tension in low-stress situations. Especially, in accordance with the results of the study, more mental guidance should be made toward those students who have a high standard for themselves.

Finally, there are some limitations in this study as well. First, this study only collected data from Chinese college students. Consequently, students from other cultural backgrounds are necessary to be included in future studies to come up with more generalized conclusions. More than that, even though the impact of personality toward the stress level is significant, there could exist more direct influential factors, or intermediaries, such as self-worth and self-efficacy. All in all, future studies can comprise more pertinent factors to dig into the college students stress management issues.

\section{References}

[1] Misra R, Mckean M, West S, Russo T. Academic stress of college students: comparison of student and faculty perceptions. College Student Journal. 2000;34(2): 236-245.

[2] Villanova P, Bownas DA. Dimensions of College Student Stress J. 1984.

[3] Feld L D, Shusterman A. Into the pressure cooker: Student stress in college preparatory high schools. J Adolescence. 2015; 41: 31-42.

[4] Judge T A, Higgins C A, Thoresen C J, Barrick M Ret. The big five personality traits, general mental ability, and career success across the life span. J Personnel psychology. 1999;52(3): 621-652.

[5] Gosling S D, Rentfrow P J, Swann Jr W B. A very brief measure of the Big-Five personality domains. J. Res. Personality. 2003;37(6): 504-528.

[6] Syed A R, Rehman K U, Kitchlew N. Impact of perceived leadership style on employees' work stress: Moderating and mediating role big 5 personality traits. J Paradigms. 2018;12(1): 6-15.

[7] Jansi A M, Anbazhagan S. The relationship between big 5 personality traits and life satisfaction of among ncc women students. International J. Management. 2017;8(2).

[8] Saklofske D H, Austin E J, Mastoras S M, Beaton L, Osborne S E. Relationships of personality, affect, emotional intelligence and coping with student stress and academic success: Different patterns of association for stress and success. J Learning Individual Differences. 2012;22(2): 251-257.

[9] Tosevski D L, Milovancevic M P, Gajic S D. Personality and psychopathology of university students. J Current Opinion in Psychiatry. 2010;23(1): 48-52.

[10] Bagherian S A, Mohammadian F, Azadi R. The relation between personality type and stress. AETAS J. History Related Disciplines. 2015;(4): 21.

[11] Han W L, Kim J E. A study on university students' personality traits and resilience. J. Emotional Behavioral Disorders. 2017. 33(3): 21-40.

[12] Kato T. Styles of handling interpersonal conflict, personality, and mental health in undergraduate students. Japanese J. Social Psychology. 2013;18(2): 78-88

[13] Holman D J, Hughes D J. Transactions between Big - 5 personality traits and job characteristics across 20 years. J Occupational and Organizational Psychology. 2021. 